\title{
A INFLUÊNCIA DA PROXIMIDADE TECNOLÓGICA E GEOGRÁFICA SOBRE A INOVAÇÃO REGIONAL NO BRASIL*
}

\author{
Eduardo Gonçalves ${ }^{* *}$ \\ Bernardo de Abreu Guelber Fajardo ${ }^{\star * *}$
}

RESUMO O objetivo deste trabalho é verificar a influência da proximidade geográfica e da proximidade tecnológica sobre a inovação regional no Brasil, medida por depósitos de patentes no período 1999-2001 para mesorregiões geográficas. Para tanto, utilizaram-se técnicas de Análise Exploratória de Dados Espaciais (AEDE) e de econometria espacial. Os dados de patentes foram organizados em quatro clusters tecnológicos segundo critérios de proximidade cognitiva, como biofarmacêutico, desenvolvimento de novos materiais, bens mecânicos e de consumo e tecnologias eletroeletrônicas, revelando um padrão de concentração da atividade tecnológica em poucas mesorregiões brasileiras. Além disso, foi calculada a medida de proximidade tecnológica de Jaffe para ponderar a vizinhança geográfica pelo grau de similaridade tecnológica das mesorregiões. Os resultados confirmam a hipótese de transbordamentos de conhecimento mediados tecnológica e geograficamente.

PALAVRAS-CHAVE: inovação; proximidade tecnológica; proximidade geográfica; patentes; transbordamentos de conhecimento

\section{THE INFLUENCE OF THE TECHNOLOGICAL PROXIMITY AND THE GEOGRAPHICAL PROXIMITY ON BRAZILIAN REGIONAL INNOVATION}

\footnotetext{
ABSTRACT The aim of this paper is to determine the influence of technological proximity and geographical proximity on Brazilian regional innovation, measured by patent applications over the period 1999-2001 for Brazilian geographical mesoregions. First, the paper undertakes an Exploratory Spatial Data Analysis (ESDA) and then uses spatial econometric techniques. According with procedures based on cognitive proximity

* Artigo enviado em 1 de fevereiro de 2010 e aprovado em 16 de dezembro de 2010.

** Doutor em Economia Regional e Urbana. Prof. Adjunto da Faculdade de Economia da UFJF e pesquisador do CNPq. Contato: eduardo.goncalvez@uff.edu.br.

*** Graduado em Ciências Econômicas pela UFJF. Contato: bguelber@hotmail.com.
} 
the patent data are organized into four technological clusters such as chemical and bio-pharmaceutical, new materials, mechanical and process technologies and electrical and electronic technologies. The four aforementioned clusters exhibit a concentrated regional pattern of technological activity over few Brazilian mesoregions. Moreover, the paper uses a Jaffe's measure of technological distance in order to construct a matrix in which the technological similarity is weighted by the geographical proximity. The results corroborate the hypothesis of geographically and technologically mediated knowledge spillovers across Brazilian mesoregions.

KEY WORDS: innovation; technological proximity; geographical proximity; patents; knowledge spillovers 


\section{INTRODUÇÃO}

A capacidade de inovar é vinculada ao desenvolvimento econômico por diferentes vertentes teóricas (ROMER, 1990; MALECKI, 1997; NELSON e WINTER, 1982). Entretanto, a capacidade de gerar essas inovações difere entre as regiões porque depende de fatores que são distribuídos regionalmente de forma desigual, como: concentração prévia de atividade produtiva (AUDRETSCH e FELDMAN, 1996); presença de infraestrutura tecnológica apropriada (FELDMAN e FLORIDA, 1994); existência de escala e atributos urbanos (SIMMIE, 2001; FELDMAN, 1999); composição da estrutura econômica regional, envolvendo seu grau de diversidade ou seu tipo de especialização setorial (FELDMAN e AUDRETSCH, 1999; GLAESER et al., 1992); "robustez institucional" a partir da presença de instituições locais, como institutos de pesquisa, universidades, agências de transferência de tecnologia, instituições de financiamento ou governamentais, que criam sinergia de interação entre os agentes locais para favorecer o aprendizado tecnológico (AMIN e THRIFT, 1994); e possibilidade de difusão de conhecimento tecnológico, intencional ou não, das instituições e empresas envolvidas com $\mathrm{P} \& \mathrm{D}$ para outras empresas com potencial inovador, localizadas nas proximidades daquelas (JAFFE et al., 1993; VARGA, 1998; FISCHER e VARGA, 2003).

Como visto, a capacidade regional de gerar inovações decorre não só da quantidade de conhecimento tecnológico que uma região consegue produzir e acumular, mas também do quanto ela consegue absorver de conhecimento gerado em regiões vizinhas (MALECKI, 1997). Há vasta literatura que investiga a existência de transbordamento de conhecimento tecnológico inter-regional, cuja origem não está associada apenas ao comércio de bens ou à mobilidade de pessoas qualificadas (FELDMAN e AUDRETSCH, 1999). O trabalho de Jaffe (1986) relaciona positivamente a produtividade da P\&D ao gasto de P\&D de firmas na mesma "vizinhança tecnológica". Jaffe (1989) destacou o efeito da pesquisa universitária sobre a atividade inovadora empresarial nas áreas de farmacêutica, tecnologia médica, eletrônica, óptica e tecnologia nuclear e também que a pesquisa universitária possuía efeito indireto sobre a inovação regional por atrair gastos de $\mathrm{P} \& \mathrm{D}$ industrial e aumentar a produtividade do $\mathrm{P} \& \mathrm{D}$ universitário. Jaffe et al. (1993) argumentam que as patentes citam mais frequentemente outras patentes de áreas geográficas próximas à da patente de origem, tomando isso como evidência de que os transbordamentos de conhecimento são geograficamente localizados.

Uma das hipóteses comuns a todos esses estudos é a de que o conhecimento tecnológico, para ser disseminado de forma bem sucedida, requer contatos face a face e, consequentemente, proximidade geográfica, tendo em vista a natureza tácita do conhecimento transmitido. A outra é que a proximidade tecnológica da firma ou região vizinha também importa, tendo em vista que os efeitos benéficos da proximidade espacial podem não ser suficientes para promover a inovação regional se não 
houver também similaridade tecnológica entre as regiões. Nesta hipótese, a proximidade tecnológica seria também um fator importante para entender a influência da vizinhança sobre a atividade tecnológica regional.

No caso brasileiro, além dos trabalhos que constataram a existência de concentração espacial das atividades inovadoras no centro-sul do País (DINIZ e GONÇALVES, 2001; ALBUQUERQUE et al., 2002; GONÇALVES, 2007), há evidências de que existem transbordamentos de conhecimento tecnológico no Brasil, tendo em vista que a atividade tecnológica de microrregiões vizinhas apresenta-se como determinante positivo e significativo da atividade tecnológica regional (GONÇALVES e ALMEIDA, 2009). Entretanto, ainda não é possível constatar na literatura brasileira se o grau de similaridade tecnológica entre as regiões afeta a ocorrência de transbordamentos de conhecimento tecnológico. Dessa forma, o objetivo do presente trabalho é o de avaliar a influência da proximidade tecnológica $v i s-\grave{a}-v i s$ a proximidade geográfica sobre a atividade tecnológica regional no Brasil.

Para tanto, este trabalho divide-se em quatro seções além desta introdução. $\mathrm{Na}$ segunda seção, realiza-se uma revisão da literatura que relaciona o acúmulo de conhecimento tecnológico, seus transbordamentos e o grau de similaridade tecnológica entre firmas e regiões. A terceira seção aborda aspectos metodológicos vinculados à Análise Exploratória de Dados Espaciais (AEDE) e à Econometria Espacial, além de apresentar as variáveis utilizadas, tomando por base a Função de Produção de Conhecimento de Griliches (1979). A quarta seção realiza uma análise descritiva da base de dados e apresenta os resultados econométricos. Por fim, a quinta seção conclui o artigo.

\section{REVISÃO DE LITERATURA}

\subsection{IMPORTÂNCIA DA INOVAÇÃO PARA O CRESCIMENTO ECONÔMICO}

A evolução dos modelos econômicos do mainstream que abordam os fatores determinantes do crescimento econômico tem sido favorável à incorporação da inovação como variável chave do processo de crescimento. A teoria de Domar (1946) representaria uma fase em que os modelos econômicos, essencialmente de curto prazo, destacavam apenas a acumulação do "capital físico", como maquinarias e equipamentos, como fator principal para explicar o crescimento econômico regional. Em uma segunda fase, a teoria de Solow (1956), que se baseia na função de produção neoclássica, considera essencialmente capital e trabalho como fatores de crescimento econômico, tomando o progresso tecnológico como um fator essencialmente exógeno ao modelo do crescimento. Arrow (1962) propõe uma variante do modelo de Solow, destacando o conhecimento como um fator de produção que não pode ser excluído da análise econômica. O autor baseia-se na visão de que a aquisição de conhecimento é decorrente da experiência e que a elevação do nível de produtividade da economia poderia ser produto do 
montante de experiência adquirido na profissão ou na elaboração de um determinado produto ou processo. Em uma terceira fase das teorias de crescimento estão os "modelos de crescimento endógeno". Em Romer (1990), o conhecimento acumulado e seus transbordamentos são a base do crescimento endógeno de uma região. Lucas (1988) considera os transbordamentos localizados como uma parte do crescimento regional. Esses modelos têm como base teórica o papel da tecnologia e do conhecimento no desenvolvimento econômico regional de longo prazo.

A partir da vinculação entre crescimento econômico e acumulação e difusão de conhecimento, duas linhas de investigação têm sido exploradas, segundo Henderson (2007). Na primeira, há um enfoque macro que aborda o papel dos transbordamentos de conhecimento e sua vinculação com o crescimento da produtividade e tamanho das cidades (BLACK e HENDERSON, 1999; GLAESER et al., 1999). Na segunda, volta-se para o nível micro da análise em que a natureza dos transbordamentos de conhecimento e o processo pelo qual eles são difundidos são abordados (JAFFE et al., 1993; ALMEIDA e KOGUT, 1999).

Opinião similar pode ser encontrada em Orlando (2000), no qual os transbordamentos advindos da atividade inovadora desempenham papel central em uma nova e importante fase da literatura internacional, na qual se estabelecem novos modelos teóricos para o crescimento econômico. Estes modelos buscam explorar o duplo aspecto (público e privado) da natureza dos novos conhecimentos criados através de investimentos em atividades inovadoras. Os resultados da investigação destacam que a atividade inovadora é entendida como não-rival e parcialmente excludente, já que investimentos privados aplicados no desenvolvimento de novas tecnologias podem aumentar o conhecimento e a produtividade de outros setores.

A próxima subseção procura realizar uma breve resenha dos trabalhos empíricos que abordam os transbordamentos de conhecimento tecnológico.

\subsection{TRANSBORDAMENTOS DE CONHECIMENTO: O PAPEL DA PROXIMIDADE GEOGRÁFICA E DA PROXIMIDADE TECNOLÓGICA}

A literatura geralmente ressalta que os transbordamentos de conhecimento tecnológico são geograficamente delimitados e que exercem impacto positivo sobre o desempenho inovador das regiões (JAFFE, 1989; JAFFE et al., 1993), ainda que exista evidência mais recente de que a inserção em redes de cooperação pode torná-los menos restritos geograficamente, como no caso de firmas francesas de biotecnologia (GALLIÉ, 2009).

A premissa que fundamenta a existência de transbordamentos localizados geograficamente é a de que a proximidade geográfica facilita a interação, a coordenação 
e a comunicação entre os agentes, além de diminuir a intensidade de buscas por informações, conhecimento e oportunidades de lucro (FELDMAN, 1999). A necessidade de contatos face a face é tanto mais importante quanto maior o caráter tácito do conhecimento envolvido no processo inovador.

O conhecimento tácito caracteriza-se pela dificuldade de transmissão à distância, pois por maior que seja a habilidade de um indivíduo em alguma função, ele pode nunca ter completa consciência de tudo que realmente sabe e de tudo que é realmente necessário para a execução dessa tarefa aparentemente simples para o próprio, além de não conseguir explicitar seu conhecimento apenas com palavras (POLANYI, 1967). Para aquisição de tal conhecimento necessitam-se experiências, observações pessoais dos agentes e interações sociais, tornando-se, portanto, dificilmente transbordável por longas distâncias ou por diferentes contextos sociais. Esse não é estabelecido de forma explícita, requerendo experiência de trabalho comum através de relação face a face (GERTLER, 2003), ainda que tais interações não sejam exigidas durante todas as fases do processo inovador, como defende Torre (2008).

Ao contrário, o conhecimento codificado, ou informação, pode ser trocado facilmente através da distância e ser expresso com auxílio de material físico, linguagem verbal, escrita (POLANYI, 1967; RALLET e TORRE, 1999; GERTLER, 2003). Nesse sentido, o conhecimento codificado poderia transbordar com maior facilidade, em relação ao tácito, tanto para regiões mais próximas quanto para as mais distantes (FAGGIAN e McCANN, 2004).

Por essas razões, os trabalhos que evidenciam a existência de transbordamentos de conhecimento concluem que o fluxo de conhecimento é menor, quanto maior é a distância entre a região de origem e a de destino do novo conhecimento (PACI e USAI, 2007), existindo um padrão de decréscimo da importância dos transbordamentos à medida que aumenta a distância geográfica (VARGA, 1998; FISCHER e VARGA, 2003; MORENO et al., 2003).

Greunz (2003) argumenta que idioma e hábitos regionais característicos são mais facilmente aceitos e adotados quanto maior for a proximidade entre os agentes. Entretanto, também é possível constatar que os transbordamentos de conhecimento seriam mais importantes para setores industriais em que há maior propensão à aglomeração por causa da dependência de externalidades de conhecimento, particularmente naqueles em que os gastos de $\mathrm{P} \& \mathrm{D}$, a pesquisa universitária e o trabalho qualificado são insumos importantes (FELDMAN, 1999; AUDRETSCH e FELDMAN, 1996). Há evidências de que a propensão à aglomeração da inovação na Europa se deve ao papel exercido pelos transbordamentos de conhecimento tecnológico, controladas outras características regionais, como a concentração geográfica da produção por setores (MORENO et al., 2005a). Fischer e Varga (2003) demonstram que, 
para a Áustria, as externalidades de conhecimento, provenientes de universidades, são mais prevalescentes em setores de alta tecnologia, nos quais o conhecimento tecnológico e científico assume maior preponderância.

De forma similar, as patentes citam, de forma desproporcionalmente maior, outras patentes que pertencem a localizações geográficas próximas à patente originária, demonstrando um fluxo de conhecimento localizado (JAFFE et al., 1993).

Outra premissa que está presente em vários desses estudos é o perfil tecnológico das firmas e regiões e a maneira pela qual essa característica influencia a magnitude e a direção dos transbordamentos de conhecimento. Segundo Orlando (2000), os transbordamentos são maiores entre os vizinhos tecnológicos porque a capacidade do uso produtivo do conhecimento por outras firmas depende também do grau de similaridade tecnológica entre as firmas. Cada tecnologia possui algum conjunto de aplicações que é exclusivo. A razão para isso é que cada tecnologia encarna uma espécie de "linguagem" única e diz respeito a um conjunto específico de aplicações. Dessa forma, pesquisadores do campo tecnológico são mais suscetíveis a publicar e ler artigos nas mesmas fontes de informação, como navegar em um conjunto comum de páginas web, usar as mesmas revistas e operar nas mesmas organizações profissionais. Outro aspecto que se deve considerar é que o idioma e os hábitos regionais característicos são mais facilmente aceitos e adotados quanto maior for a proximidade entre os agentes (GREUNZ, 2003). Patel e Pavitt (1995) consideram que as firmas têm maior possibilidade de encontrar outras com perfil tecnológico similar dentro do seu próprio setor do que em outros.

De fato, Moreno et al. (2005b) evidenciam que as externalidades transbordam mais facilmente entre as regiões quando há similaridade tecnológica entre as firmas. Com base em 175 regiões de 17 países europeus, os autores afirmam que a inovação é positivamente dependente de fatores regionais internos, como gastos em $\mathrm{P} \& \mathrm{D}$ e economias de aglomeração, e transbordamentos espaciais de atividade inovadora realizada por outras regiões. Os resultados mostraram que os efeitos de proximidade espacial são potencializados quando as regiões são tecnologicamente homogêneas. Da mesma forma, Autant-Bernard (2001) reconhece que divisões administrativas francesas que possuem perfil tecnológico similar ao de seus vizinhos são mais inovadoras, sendo o capital humano o principal fator pelo qual os transbordamentos geográficos de conhecimento ocorreriam.

Com base em Breschi et al. (1998), é possível constatar que diferentes medidas de proximidade tecnológica foram propostas. Scherer (1982) mediu fluxos de tecnologia entre setores industriais, baseando-se na utilização de uma matriz, calculada através dos dados de gastos em $\mathrm{P} \& \mathrm{D}$ de uma indústria de origem e a indústria em que os produtos e processos resultantes do insumo inovador ocorreram. De acordo com 
o método, duas indústrias devem, portanto, ser consideradas como próximas uma da outra se um elevado percentual de P\&D realizado em um setor for incorporado e utilizado no outro setor.

A partir de dados de patentes norte-americanas, distribuídas por diferentes classes tecnológicas, Jaffe $(1986,1989)$ mediu proximidade tecnológica através de um coeficiente de correlação entre os vetores que representam a distribuição das patentes pelas 49 classes em que foram agrupadas. Verspagen (1997), por outro lado, usa dados de patentes de forma diferente. $\mathrm{O}$ autor baseia-se nos códigos de classificação primários e complementares que estão disponíveis nos documentos de patentes. Os primeiros representariam o setor produtor de conhecimento e os segundos, tomados como subprodutos do principal objetivo da patente, indicariam os transbordamentos tecnológicos para outros setores industriais.

Moreno et al. (2003) ressalta que parte da literatura, como Verspagen (1997), usa tabelas de insumo-produto para o cálculo da proximidade tecnológica. Nesse sentido, as compras e vendas dos diferentes setores industriais representariam, respectivamente, externalidades oriundas de ofertantes ou de clientes. Os setores industriais usuários de insumos similares também usariam tecnologias semelhantes.

\section{METODOLOGIA}

\subsection{CONSTRUÇÃO E ANÁLISE DA BASE DE DADOS}

Os dados de patentes utilizados nesse trabalho são oriundos do Instituto Nacional de Propriedade Industrial (INPI) e referentes ao período 1999-2001. Os dados totalizam 16.884 patentes, sendo distribuídos por 121 mesorregiões geográficas com pelo menos uma patente, do total de 137 mesorregiões existentes. A escolha da unidade de análise territorial (mesorregiões) ocorreu em função de duas razões. Em primeiro lugar, procurou-se minimizar a ausência de unidades territoriais com patenteamento zero, como no caso de municípios e microrregiões, o que inviabiliza o cálculo da matriz de proximidade tecnológica. Em segundo lugar, pelo menos no que tange aos transbordamentos de conhecimento tecnológico considerando a vizinhança puramente geográfica, os resultados poderão ser comparados às evidências de Gonçalves e Almeida (2009) para mostrar se as evidências brasileiras são sensíveis à unidade territorial de análise.

A partir dos códigos que identificam as patentes, os dados foram organizados em duas etapas. Na primeira, foram consideradas as 118 possíveis classes tecnológicas, segundo a International Patent Classification (IPC), para cálculo da medida de proximidade tecnológica, usada inicialmente por Jaffe (1986). Dessa forma, mediremos similaridade ou distância tecnológica por uma matriz, que será calculada por meio de dados de depósitos de patentes desagregados setorialmente para cada mesorregião. A medida de correlação é dada por: 


$$
P_{i j}=\left(\sum_{k=1}^{k} f_{i k} f_{j k}\right) P_{i j}=\left(\sum_{k=1}^{k} f_{i k} f_{j k}\right)
$$

onde $\mathrm{f}_{\mathrm{ik}}$ é a participação de uma classe de patente particular k no total de patentes da mesorregião i. Essa medida toma valor unitário se regiões possuem características tecnológicas idênticas, e vice-versa. Dessa forma, quanto mais próxima da unidade a medida fosse, mais homogêneas tecnologicamente seriam as mesorregiões. Por outro lado, quanto menor o indicador e mais próximo de zero, as mesorregiões seriam mais diferentes no que tange ao seu perfil tecnológico.

O indicador de correlação mostrado permite a construção de uma matriz de proximidade tecnológica, tendo em vista que as correlações parciais entre duas mesorregiões representam o grau de similaridade tecnológica entre elas. Com essa metodologia, pretende-se estabelecer o quão próxima uma região se apresenta em termos tecnológicos de outra, testando a hipótese apregoada pela literatura internacional de que a proximidade geográfica exerce maior influência na geração de transbordamentos de conhecimento quanto maior for a semelhança tecnológica entre as regiões.

Além de destacar os papéis que a proximidade espacial e a proximidade tecnológica exercem isoladamente na inovação, pretende-se estimar também a influência conjunta de ambos os efeitos. Para tanto, realiza-se a interação entre uma matriz de pesos espaciais qualquer e a matriz tecnológica descrita acima, obtendo-se, portanto, a influência espacial que uma região exerce em sua região vizinha, ponderando-se por sua semelhança tecnológica, $\mathrm{Na}$ segunda etapa, as patentes foram inicialmente agrupadas em 30 subdomínios tecnológicos a partir das classes tecnológicas (OST, 2000) - ver Tabela $1^{1}$.

\footnotetext{
${ }^{1}$ Os subdomínios tecnológicos são: Componentes Elétricos, Audiovisual, Telecomunicações, Informática, Semicondutores, Ótica, Análise-Mensuração-Controle, Engenharia Médica, Química Fina Orgânica, Química Macromolecular, Farmacêuticos-Cosméticos, Biotecnologia, Materiais-Metalurgia, Produtos Agrícolas e Alimentares, Química de Base, Engenharia Química, Tratamento de Superfícies, Têxtil e Papel, Procedimentos Térmicos, Meio-Ambiente, Máquinas-ferramentas, Motores-BombasTurbinas, Componentes Mecânicos, Manutenção-Gráfica, Aparelhos Agrícolas e Alimentares, Transportes, Técnicas Nucleares, Espacial-Armamentos, Consumo das Famílias e Construção Civil.
} 
TABELA 1 - Metodologia para definição dos clusters tecnológicos utilizando-se das definições de Subdomínios Tecnológicos proposta pela OST seguindo a classificação das Classes de Patentes definida pela Organização Mundial da propriedade Intelectual (OMPI)

\begin{tabular}{|c|c|c|}
\hline $\begin{array}{l}\text { Cluster Tecnológico } \\
\text { (Brechi et al., 1998) }\end{array}$ & $\begin{array}{l}\text { Subdomínios tecnológicos } \\
\text { (OST, 2000) }\end{array}$ & $\begin{array}{c}\text { Classes de patentes } \\
\text { (OMPI) }\end{array}$ \\
\hline Biofarmacéutico & $\begin{array}{l}\text { Química orgânica } \\
\text { Farmacêutico e cosméticos } \\
\text { Biotecnologia } \\
\text { Qímica de base }\end{array}$ & $\begin{array}{l}\text { C07C, D, F, H, J, K } \\
\text { A61K } \\
\text { C07G, C12M, N, P, Q, S } \\
\text { A0IN, C05, C07B, C08C, C09B, C, F, G, H, K, } \\
\text { C10B, L, M, C11B, C, D }\end{array}$ \\
\hline $\begin{array}{l}\text { Desenvolvimento } \\
\text { de novos materiais }\end{array}$ & $\begin{array}{l}\text { Química macromolecular } \\
\text { Procedimentos técnicos } \\
\text { Tratamento de superfícies } \\
\text { Trabalho com materiais }\end{array}$ & $\begin{array}{l}\text { C08B, F, G, H, K, L, C09D, I } \\
\text { B01, B02, B03, B04, B05, B06, B07, B08, F25J, F26 } \\
\text { B05C, D, B32, C23, C25, C30 } \\
\text { A41H, A43B, A46D, B28, B29, B31, C03B, C08I, } \\
\text { C14, D01, D02, D03, D04B, C, G, H, D06B, C, G, } \\
\text { H, J, L, M, P, Q, D21 } \\
\text { C01, C03C, C04, C21, C22, B22 } \\
\text { A62D, B09, C02, F01N, F23G, J } \\
\text { A61B, C, D,F, G, H, J, L, M, N } \\
\text { A01H, A21D, A23B, C, D, F, G, J, K, L, C12C, F, G, }\end{array}$ \\
\hline $\begin{array}{l}\text { Bens mecânicos } \\
\text { e de consumo }\end{array}$ & $\begin{array}{l}\text { Engenharia médica } \\
\text { Produtos agrícolas e alimentares } \\
\text { Procedimentos térmicos } \\
\text { Máquinas-ferramentas } \\
\text { Motores, bombas e turbinas } \\
\text { Componentes mecânicos } \\
\text { Manutenção gráfica } \\
\text { Aparelhos agrícolas e alimentares } \\
\text { Transportes } \\
\text { Técnicas nucleares } \\
\text { Espacial-armamento } \\
\text { Consumo das famílias }\end{array}$ & $\begin{array}{l}\text { H, J, C13D, F, J, K } \\
\text { F22, F23B, C, D, H, K, L, M, N, Q, F24, F25B, C, } \\
\text { F27, F28 } \\
\text { B21, B23, B65B, C, D, F, G, H, B66, B67 } \\
\text { F01A, B, C, D, E, F, G, H, I, J, K, L, M, N, F02, F03, } \\
\text { F04, F23R } \\
\text { F15, F16, F17, G05G } \\
\text { B25J, B41, B65B, C, D, F, G, H, B66, B67 } \\
\text { B41, B65B, C, D, F, G, J, K, L, M, A21B, C, A22, } \\
\text { A23N, P, B02B, C12L, C13C, G, H } \\
\text { B60, B61, B62, B63B, C, H, J, B64B, C, D, F } \\
\text { G01T, G21, H05G, H } \\
\text { B60, B61, B62, C, D, F, G, H, B66, B67 } \\
\text { A24, A41B, C, D, F, G, A42, A43B, C, A44, A45, } \\
\text { A46B, A47, A62B, C, A63, B25B, C, D, F, G, H, } \\
\text { B26B, B42, B43, B44, B68, D04D, D06F, N, D07, } \\
\text { F25D, G10B, C, D, F, G, H, K }\end{array}$ \\
\hline & Construção civil & $\mathrm{E} 01, \mathrm{E} 02, \mathrm{E} 03, \mathrm{E} 04, \mathrm{E} 05, \mathrm{E} 06, \mathrm{E} 21$ \\
\hline Eletroeletrônico & $\begin{array}{l}\text { Componentes elétricos } \\
\text { Audiovisual } \\
\text { Telecomunicações } \\
\text { Informática } \\
\text { Semicondutores } \\
\text { Ótica } \\
\text { Análise, mensuração e controle }\end{array}$ & $\begin{array}{l}\text { F21, G05F, H01B, C, F, G, H, J, K, M, R, T, H02, } \\
\text { H05B, C, F, K, } \\
\text { G09F, G, G11B, H03F, G, J, H04N, R, S } \\
\text { G08C, H01P, Q, H03B, C, D, H, K, L, M, H04B, H, } \\
\text { J, K, L, M, Q, } \\
\text { G06, G11C, G10L } \\
\text { H01L } \\
\text { G02, G03B, C, D, F, G, H, H01S } \\
\text { G01B, C, D, F, G, H, J, K, L, M, N, P, R, S, V, W, } \\
\text { G04, G05B, D, G07, G08B, G, G09B, C, D, G12 }\end{array}$ \\
\hline
\end{tabular}


Posteriormente, utilizou-se o procedimento de BRESCHI et al. (1998; 2003) que agrupa os subdomínios, em função de sua proximidade cognitiva, em quatro clusters tecnológicos ${ }^{2}$ a saber: biofarmacêutico, desenvolvimento de novos materiais, bens mecânicos e de consumo e tecnologias eletroeletrônicas (Tabela 1). As especializações das mesorregiões brasileiras nos clusters mencionados serão avaliadas através da AEDE.

\subsection{ANÁLISE EXPLORATÓRIA DE DADOS ESPACIAIS (AEDE) E ECONOMETRIA ESPACIAL}

Para a análise dos clusters tecnológicos no Brasil será realizada a AEDE, que, de acordo com Anselin (1999), visa estabelecer padrões de associações espaciais, ou seja, busca identificar se os valores de uma variável em certa região dependem dos valores desse atributo nas regiões vizinhas, observando para tanto a estatística "I de Moran" (MORAN, 1948). Além disso, serão elaborados os mapas de clusters espaciais para cada um dos clusters tecnológicos, definidos na subseção anterior.

Para testar a influência dos transbordamentos de conhecimento na inovação nacional, utiliza-se o método econométrico-espacial. Segundo Anselin (1999), essa metodologia, ao contrário dos métodos econométricos tradicionais, considera a influência dos efeitos espaciais, como a dependência e a heterogeneidade espacial, evitando a possibilidade de obtenção de resultados enviesados, devido aos problemas de inferência estatística que esses efeitos poderiam causar. A dependência espacial será modelada segundo Anselin $(1988 ; 1999)$.

As matrizes de pesos espaciais usadas nesse artigo são definidas a seguir:

1) Matriz de contiguidade binária (W_QUEEN): calculada de acordo com o critério Queen (ANSELIN, 1999), para captar dependência espacial entre as mesorregiões com fronteiras comuns;

2) Matriz de distância inversa ao quadrado (W_INVDIST2): calculada a partir da distância dos centróides das mesorregiões ao quadrado, para controlar efeitos espaciais provenientes de áreas geográficas mais distantes, dado que a intensidade da influência é decrescente em função do aumento da distância geográfica;

\footnotetext{
${ }^{2}$ A distância entre os subdomínios tecnológicos baseou-se na ocorrência simultânea de códigos tecnológicos (IPC), tanto os principais quanto os complementares, atribuídos aos documentos de patentes. A frequência com que os códigos de classificação ocorrem simultaneamente no mesmo documento de patente foi interpretada pelos autores como indicadora da força da relação entre áreas tecnológicas. Dessa forma, assumiu-se que classes tecnológicas presentes na mesma patente deveriam compartilhar a mesma base de conhecimento, sendo similares e próximas de uma perspectiva cognitiva (BRESCHI et al., 1998).
} 
3) Matriz de distância tecnológica (W_TECH): calculada por meio de dados de depósitos de patentes desagregados setorialmente para cada mesorregião, conforme detalhado na seção 3.1 ;

4) Matriz de contiguidade binária ponderada pela distância tecnológica (W PQUEEN): calculada segundo a mesma metodologia exposta na matriz (W_QUEEN), porém ponderando-a pela matriz de proximidade tecnológica (W_TECH);

5) Matriz de contiguidade binária dos vizinhos até segunda ordem ponderada pela distância tecnológica (W_PQUEEN2): utiliza a mesma metodologia da matriz (W_QUEEN), porém considera como área de influência as regiões vizinhas até segunda ordem, além de ser ponderada pela matriz de proximidade tecnológica;

6) Matriz de contiguidade binária dos vizinhos até terceira ordem ponderada pela distância tecnológica (W_PQUEEN3): utiliza a mesma metodologia da matriz (W_QUEEN), com área de influência da vizinhança até terceira ordem e ponderação pela matriz de proximidade tecnológica (W_TECH);

7) Matriz de distância inversa ponderada pela distância tecnológica (W PINVDIST): calculada utilizando-se da mesma metodologia da matriz W_INVDIST2, porém, ponderando-a pela matriz de proximidade tecnológica.

\subsection{A FUNÇÃo PRODUÇÃO DE CONHECIMENTO E O MODELO EMPÍRICO}

A estrutura teórica desse trabalho está baseada na Função Produção de Conhecimento (FPC), desenvolvida por Griliches (1979) e modificada por Jaffe (1989). Tal função estabelece uma relação entre os insumos da geração de um novo conhecimento, seu processo de produção e os novos conhecimentos tecnológicos desenvolvidos. A relação entre insumo e produto da FPC será avaliada por meio de modelos econométricoespaciais.

Como medida de produto da função de produção serão considerados depósitos de patentes per capita (PATPOP), que constituem também a variável dependente do modelo de regressão espacial. Para construção dessa variável, dividiram-se os depósitos de patentes realizados por firmas e indivíduos junto ao INPI, no período 19992001, pelas pessoas residentes na respectiva mesorregião.

As variáveis independentes serão formadas por insumos regionais que representam características tecnológicas e regionais, conforme descrito a seguir:

- Densidade de Emprego (DENSPO): a variável é calculada pela razão entre o número de pessoas ocupadas e a área, em $\mathrm{km}^{2}$, da mesorregião. A utilização 
desse indicador tenta captar a influência da grande concentração espacial de empregados de funções semelhantes e/ou diferentes em uma mesma unidade territorial, a fim de construir uma proxy para as economias de aglomeração.

- Capacidade de Realização de P\&D Universitário (PHDPOP): a variável foi construída a partir de dados da CAPES sobre professores de cursos de pós-graduação stricto sensu em áreas relevantes para criação e transferência de novas técnicas para o setor produtivo. $\mathrm{O}$ número desses professores foi normalizado pela população de cada mesorregião. São considerados, para tanto, os docentes permanentes dos cursos de mestrado e doutorado das áreas de formação tecnológica, como Engenharias, Ciências Exatas e da Terra, Ciências Agrárias, Ciências Biológicas e da Saúde e Computação e Informática. A utilização desses dados justifica-se devido à ausência de informações regionalizadas sobre gastos com $\mathrm{P} \& \mathrm{D}$ universitário. Conforme Varga (1998) e Jaffe (1989) a inclusão dessa variável deve-se a fortes evidências de um efeito positivo, direto e indireto, causado pela pesquisa universitária sobre a produtividade de P\&D empresarial.

- Capacidade de Realização de P\&D Industrial (PD): serão utilizados o valor adicionado e o valor bruto da produção industrial de empresas que possuem duas características fundamentais: ter inovado em produto que fosse novo para o mercado nacional e ser exportadora. A presença desse tipo de firma na mesorregião é considerada como indicadora de capacidade de realizar $\mathrm{P} \& \mathrm{D}$ no tecido industrial da mesorregião. A maneira pela qual esta variável foi definida pode ser vista em DE Negri et al. (2004) e Lemos et al. (2005). A ausência de dados regionalizados sobre P\&D industrial é justificativa para o uso dessa proxy.

- Dummy Regional (NORSUL): variável binária que pretende captar as diferenças estruturais e institucionais da capacidade regional da inovação. A variável assumirá valor unitário se a mesorregião localizar-se nas regiões Sul e Sudeste e assumirá valor nulo se estiver nas regiões Centro-Oeste, Nordeste e Norte. Essa divisão reflete os resultados de pesquisas realizadas no País que apontam um regime de polarização da inovação nessas regiões (GONÇALVES, 2007).

Dessa forma, o modelo empírico usado nesse artigo, incorporando o termo de defasagem espacial (WPATPOP), pode ser representado por:

$\mathrm{PATPOP}=\alpha+\beta 1 \mathrm{WPATPOP}+\beta 2 \mathrm{DENSPO}+\beta 3 \mathrm{PHDPOP}+\beta 4 \mathrm{PD}+\beta 5 \mathrm{NORSUL}+\varepsilon$ 
Ressalta-se que a forma funcional proposta, além de parcimoniosa, lida com os três principais determinantes da medida de produto do novo conhecimento (patentes), que são as influências de aglomeração (MORENO et al., 2005; KOO, 2007), capacidade de realização de $\mathrm{P} \& \mathrm{D}$ empresarial e capacidade de realização de $\mathrm{P} \& \mathrm{D}$ universitário (VARGA, 1998; FELDMAN e FLORIDA, 1994), além de considerar aspectos estruturais e institucionais, que refletem características regionais específicas do Sistema Nacional de Inovação brasileiro. A partir dessa forma funcional parcimoniosa, o objetivo é verificar a influência da proximidade tecnológica vis-à-vis a proximidade geográfica, na ocorrência de transbordamentos de conhecimento tecnológico.

\section{RESULTADOS EMPÍRICOS}

A Tabela 2 apresenta as principais mesorregiões patenteadoras no $\mathrm{Brasil}^{3}$.

Constata-se que a mesorregião São Paulo é a que registra maior número de depósitos de patentes. A diferença pode ser notada quando se observa que o número de patentes dessa mesorregião supera em mais de quatro vezes o número da segunda principal (Rio de Janeiro) e em mais de nove vezes a outra mesorregião pertencente ao Estado de São Paulo (Campinas).

A Tabela 3 apresenta os números de depósitos de patentes por Unidade da Federação, segundo cada cluster tecnológico proposto por Breschi et al. (1998; 2003).

A região Norte é a região com menor participação de depósitos de patentes no período 1999-2001, com apenas 0,62\% do total nacional. Em seguida, aparecem as regiões Centro-Oeste com 3,91\% e Nordeste com 4,60\%. Cabe notar que o Distrito Federal apresenta um número considerável de patentes se comparado com os outros estados da Federação.

A região Sul, com 3.893 patentes (23,06\%), destaca-se por todos seus estados apresentarem valores acima de mil depósitos. A região Sudeste, com 11.445 patentes $(67,81 \%)$, é a líder em inovação tecnológica. Embora na região Sudeste, o Espírito Santo conta com apenas $1,29 \%$ do total nacional, contra $8,42 \%$ de Minas Gerais, 8,28\% do Rio de Janeiro e, principalmente, o Estado de São Paulo que destoa das outras UF's, apresentando aproximadamente $49,82 \%$ do total dos depósitos de patentes do País. Nesse sentido, cabe notar que sete das 20 mesorregiões apresentadas na Tabela 2 pertencem ao Estado de São Paulo.

\footnotetext{
${ }^{3}$ As mesorregiões são nomeadas de acordo com seu principal município, em termos populacionais.
} 
TABELA 2 - Principais mesorregiões brasileiras por número de depósito de patentes

\begin{tabular}{l|l}
\hline Mesorregiões & N $^{\text {patentes }}$ \\
\hline São paulo & 5.990 \\
Rio de Janeiro & 1.360 \\
Belo Horizonte & 960 \\
Curitiba & 805 \\
Porto Alegre & 798 \\
Campinas & 629 \\
Caxias do Sul & 425 \\
Sorocaba & 347 \\
Joinville & 335 \\
Brasília & 329 \\
Londrina & 325 \\
Ribeirão Preto & 291 \\
Blumenau & 282 \\
São José dos Campos & 258 \\
Piracicaba & 206 \\
Vitória & 185 \\
Recife & 178 \\
São José do Rio Preto & 160 \\
Chapecó & 156 \\
Florianópolis & 151 \\
Outras & 2.767 \\
\hline
\end{tabular}

Fonte: Elaboração própria com base em dados do INPI. 
TABELA 3 - Número absoluto e distribuição percentual dos depósitos de patentes por região e Unidades da Federação do Brasil segundo clusters tecnológicos

\begin{tabular}{|c|c|c|c|c|c|c|c|c|c|c|}
\hline \multirow{3}{*}{ Estado } & \multirow{2}{*}{\multicolumn{2}{|c|}{ Total }} & \multirow{2}{*}{\multicolumn{2}{|c|}{$\frac{\text { Cluster } 1}{\text { Biofarmacêutico }}$}} & \multirow{2}{*}{\multicolumn{2}{|c|}{$\begin{array}{c}\text { Cluster 2 } \\
\text { Desenv. de } \\
\text { novos materiais }\end{array}$}} & \multirow{2}{*}{\multicolumn{2}{|c|}{$\begin{array}{c}\text { Cluster } 3 \\
\text { Bens mecânicos/ } \\
\text { consumo }\end{array}$}} & \multirow{2}{*}{\multicolumn{2}{|c|}{$\frac{\text { Cluster } 4}{\text { eletroeletrônicos }}$}} \\
\hline & & & & & & & & & & \\
\hline & Freq. & $\%$ & Freq. & $\%$ & Freq. & $\%$ & Freq. & $\%$ & Freq. & $\%$ \\
\hline NORTE & 104 & $0,62 \%$ & 2 & $0,39 \%$ & 13 & $0,90 \%$ & 60 & $0,50 \%$ & 29 & $0,97 \%$ \\
\hline RO & 13 & $0,08 \%$ & 0 & $0,00 \%$ & 2 & $0,14 \%$ & 11 & $0,09 \%$ & 0 & $0,00 \%$ \\
\hline $\mathrm{AC}$ & 1 & $0,01 \%$ & 0 & $0,00 \%$ & 0 & $0,00 \%$ & 1 & $0,01 \%$ & 0 & $0,00 \%$ \\
\hline $\mathrm{AM}$ & 44 & $0,26 \%$ & 1 & $0,20 \%$ & 2 & $0,14 \%$ & 19 & $0,16 \%$ & 22 & $0,74 \%$ \\
\hline $\mathrm{RR}$ & 3 & $0,02 \%$ & 0 & $0,00 \%$ & 0 & $0,00 \%$ & 3 & $0,03 \%$ & 0 & $0,00 \%$ \\
\hline $\mathrm{PA}$ & 34 & $0,20 \%$ & 1 & $0,20 \%$ & 6 & $0,42 \%$ & 22 & $0,18 \%$ & 5 & $0,17 \%$ \\
\hline $\mathrm{AP}$ & 0 & $0,00 \%$ & 0 & $0,00 \%$ & 0 & $0,00 \%$ & 0 & $0,00 \%$ & 0 & $0,00 \%$ \\
\hline TO & 9 & $0,05 \%$ & 0 & $0,00 \%$ & 3 & $0,21 \%$ & 4 & $0,03 \%$ & 2 & $0,07 \%$ \\
\hline NORDESTE & 778 & $4,61 \%$ & 33 & $6,51 \%$ & 45 & $3,13 \%$ & 503 & $4,21 \%$ & 196 & $6,56 \%$ \\
\hline MA & 43 & $0,25 \%$ & 1 & $0,20 \%$ & 3 & $0,21 \%$ & 24 & $0,20 \%$ & 15 & $0,50 \%$ \\
\hline PI & 18 & $0,11 \%$ & 0 & $0,00 \%$ & 0 & $0,00 \%$ & 12 & $0,10 \%$ & 6 & $0,20 \%$ \\
\hline $\mathrm{CE}$ & 156 & $0,92 \%$ & 9 & $1,78 \%$ & 9 & $0,63 \%$ & 89 & $0,75 \%$ & 49 & $1,64 \%$ \\
\hline $\mathrm{RN}$ & 53 & $0,31 \%$ & 2 & $0,39 \%$ & 9 & $0,63 \%$ & 33 & $0,28 \%$ & 9 & $0,30 \%$ \\
\hline $\mathrm{PB}$ & 56 & $0,33 \%$ & 2 & $0,39 \%$ & 4 & $0,28 \%$ & 36 & $0,30 \%$ & 14 & $0,47 \%$ \\
\hline $\mathrm{PE}$ & 204 & $1,21 \%$ & 12 & $2,37 \%$ & 13 & $0,90 \%$ & 135 & $1,13 \%$ & 43 & $1,44 \%$ \\
\hline $\mathrm{AL}$ & 35 & $0,21 \%$ & 1 & $0,20 \%$ & 1 & $0,07 \%$ & 24 & $0,20 \%$ & 9 & $0,30 \%$ \\
\hline SE & 25 & $0,15 \%$ & 0 & $0,00 \%$ & 1 & $0,07 \%$ & 17 & $0,14 \%$ & 7 & $0,23 \%$ \\
\hline BA & 188 & $0,11 \%$ & 6 & $0,18 \%$ & 5 & $0,35 \%$ & 133 & $1,11 \%$ & 44 & $1,47 \%$ \\
\hline SUDESTE & 11.447 & $67,80 \%$ & 353 & $69,63 \%$ & 1.013 & $70,35 \%$ & 8.064 & $67,53 \%$ & 2.015 & $67,39 \%$ \\
\hline MG & 1422 & $8,42 \%$ & 48 & $9,47 \%$ & 156 & $10,83 \%$ & 909 & $7,61 \%$ & 308 & $10,30 \%$ \\
\hline ES & 217 & $1,29 \%$ & 4 & $0,79 \%$ & 14 & $0,97 \%$ & 164 & $1,37 \%$ & 35 & $1,17 \%$ \\
\hline RJ & 1398 & $8,28 \%$ & 61 & $12,03 \%$ & 106 & $7,36 \%$ & 995 & $8,33 \%$ & 236 & $7,89 \%$ \\
\hline SP & 8410 & 48,91 & 240 & 47,34 & 737 & 51,18 & 5996 & $50,21 \%$ & 1436 & 48,03 \\
\hline SUL & 3895 & $23,07 \%$ & 84 & $16,57 \%$ & 347 & $24,10 \%$ & 2855 & $23,91 \%$ & 607 & $20,30 \%$ \\
\hline PR & 1389 & $8,23 \%$ & 35 & $6,90 \%$ & 90 & $6,25 \%$ & 1013 & $8,48 \%$ & 251 & $8,39 \%$ \\
\hline SC & 1034 & $8,72 \%$ & 27 & $5,33 \%$ & 156 & $10,83 \%$ & 1063 & $8,90 \%$ & 226 & $7,56 \%$ \\
\hline RS & 1472 & $8,72 \%$ & 27 & $5,33 \%$ & 156 & 10,83 & 1063 & $8,90 \%$ & 226 & $7,56 \%$ \\
\hline CENTRO-OESTE & 660 & $3,91 \%$ & 35 & $6,90 \%$ & 22 & $1,53 \%$ & 460 & $3,85 \%$ & 143 & $4,78 \%$ \\
\hline MS & 56 & $0,33 \%$ & 0 & $0,00 \%$ & 1 & $0,07 \%$ & 44 & $0,37 \%$ & 11 & $0,37 \%$ \\
\hline MT & 86 & $0,51 \%$ & 0 & $0,00 \%$ & 2 & $0,14 \%$ & 72 & $0,60 \%$ & 12 & $0,40 \%$ \\
\hline GO & 189 & $1,12 \%$ & 8 & $1,58 \%$ & 7 & $0,49 \%$ & 146 & $1,22 \%$ & 28 & $0,94 \%$ \\
\hline DF & 329 & $1,95 \%$ & 27 & $5,33 \%$ & 12 & $0,83 \%$ & 198 & $1,66 \%$ & 92 & $3,08 \%$ \\
\hline Total & 16.884 & $100 \%$ & 507 & $100 \%$ & 1.440 & $100 \%$ & 11.942 & $100 \%$ & 2.990 & $100 \%$ \\
\hline
\end{tabular}




\subsection{RESULTADOS DA AEDE}

Na Figura 1 apresentam-se os mapas de clusters espaciais para os depósitos de patentes segundo clusters tecnológicos ${ }^{4}$. Nota-se a existência de uma autocorrelação espacial positiva entre as mesorregiões.

O cluster tecnológico biofarmacêutico (Figura 1a) reúne setores como química de base, química orgânica, farmacêutico, cosmético e biotecnológico. Tal cluster apresenta o maior coeficiente I de Moran, denotando maior grau de autocorrelação espacial. As mesorregiões de destaque são, no padrão "Alto-Baixo", Fortaleza (CE), sendo que no padrão "Alto-Alto" destacam-se São Paulo (SP), Campinas (SP), Piracicaba (SP) e Curitiba (PR).

Lemos et al. (2009) notam que alguns dos subdomínios tecnológicos componentes desse cluster (química de base, química orgânica, farmacêutica-cosméticos e biotecnologia) possuem mais de $80 \%$ de seus registros realizados por não-residentes. Isso significa que a capacidade nacional de desenvolvimento tecnológico nesses setores é extremamente limitada, o que dificulta não só a geração do novo conhecimento bem como a capacidade de apropriação do mesmo e sua reversão em possíveis benefícios econômicos nacionais.

Cabe destacar, porém, que, nas mesorregiões destacadas anteriormente, há a presença de filiais de laboratórios farmacêuticos multinacionais que se instalam nessas regiões para a produção de fármacos. Porém, tais empresas importam a maioria de suas matérias-primas de alto valor agregado de suas sedes e de outros países líderes em tecnologia, não sendo capazes de internalizar grande parte do processo inovador.

O segundo cluster inclui uma coleção de classes tecnológicas, tendo como denominador comum o fato de estarem relacionadas ao desenvolvimento, tratamento e transformação de novos materiais. Dessa forma, incluem-se os setores de química macromolecular, procedimentos técnicos, tratamento de superfície, trabalhos com materiais, metalurgia e de meio-ambiente e poluição (BRESCHI et al., 1998).

${ }^{4} \mathrm{~A}$ matriz de peso espacial usada para o cálculo foi do tipo Queen. 


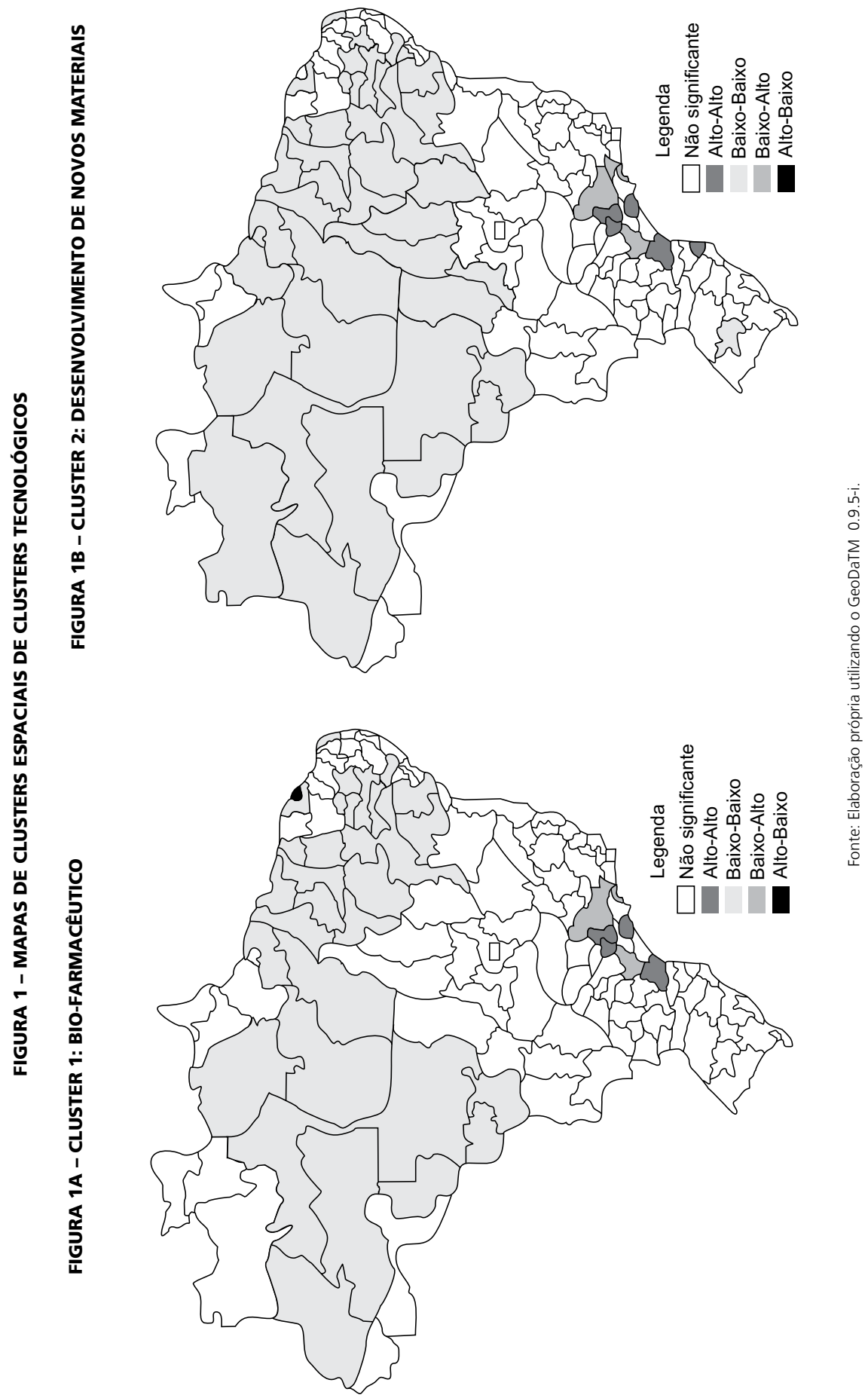




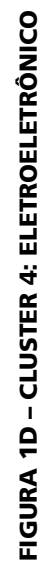

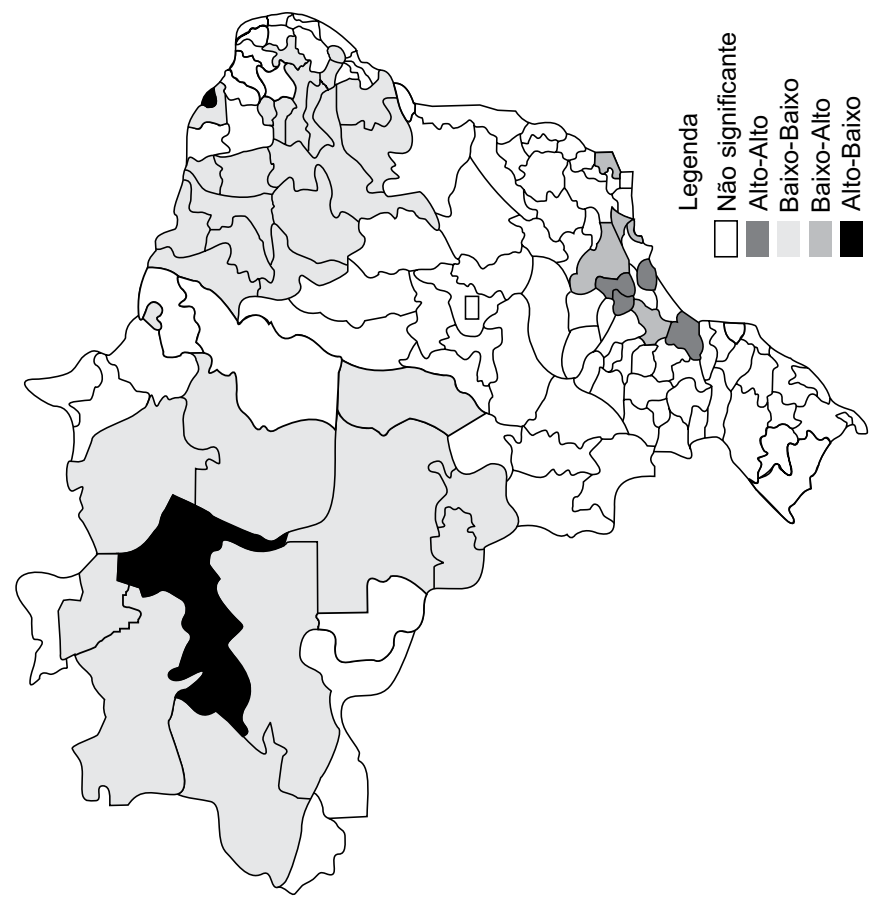

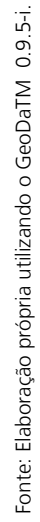

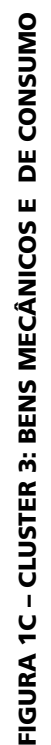

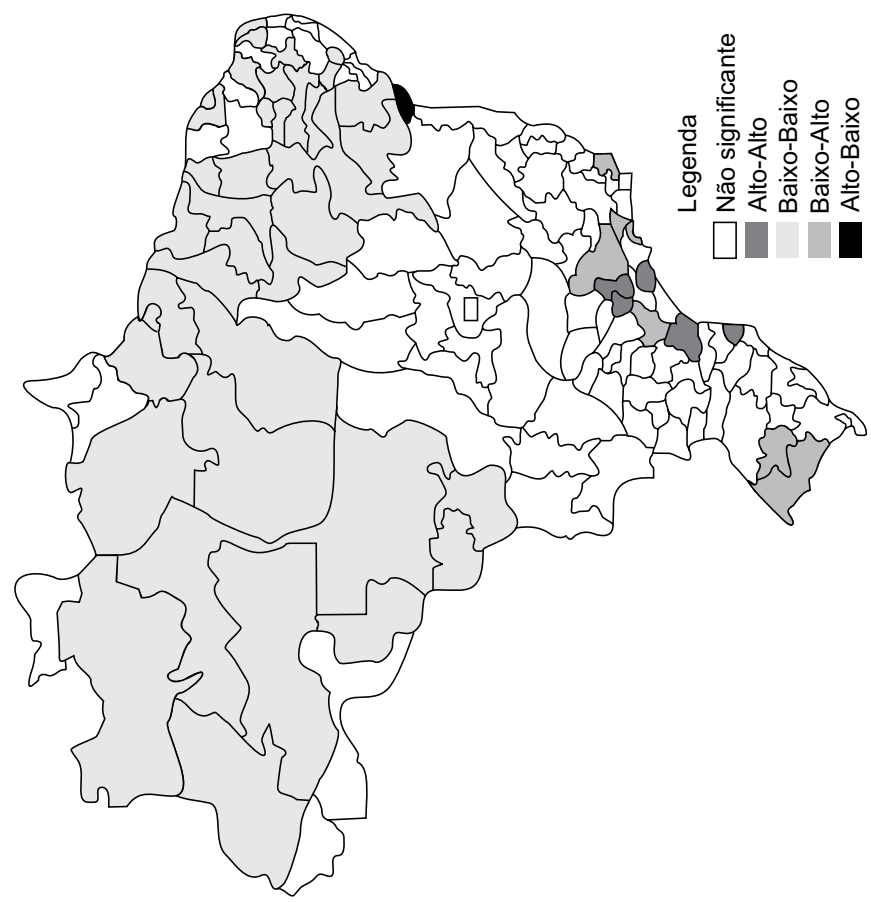


Novamente, a autocorrelação espacial se faz positivamente presente, cabendo papel de destaque aos agrupamentos do tipo "Baixo-Baixo" das regiões Norte, Nordeste e Centro-Oeste e do tipo "Alto-Alto" nas regiões Sudeste e Sul. As mesorregiões que mais se destacam seguem o padrão "Alto-Alto", sendo São Paulo (SP), Campinas (SP), Piracicaba (SP), Curitiba (PR) e Florianópolis (SC) - Figura $1 b$.

O processo de integração da economia brasileira com os padrões mundiais exige de certos produtos algumas propriedades que necessitam da combinação de vários materiais convencionais, denominados materiais híbridos. Destacam-se, por exemplo, as indústrias de materiais de plásticos que são usuárias de insumos de produção, concentradas no Sul e no Sudeste do País.

Lemos et al. (2009) notam que alguns dos subdomínios tecnológicos componentes desse cluster (tratamento de superfícies e de química macromolecular) possuem mais de $80 \%$ de seus registros realizados por não-residentes, destacando a dificuldade de geração e apropriação de inovações nesses setores.

$\mathrm{O}$ terceiro cluster refere-se aos processos mecânicos e tecnológicos, além da produção de certos bens de consumo. Esse é o cluster com maior diversidade de classes de patentes, concentrando os setores de engenharia médica, procedimentos térmicos, produtos e aparelhos agrícolas e alimentares, máquinas-ferramentas, motores, bombas e turbinas, componentes mecânicos, indústria gráfica, transportes, técnicas nucleares e espaciais, armamentos, construção civil e outros produtos de consumo familiar.

A análise desse cluster apresenta, novamente, autocorrelação espacial positiva, com destaque para o Sul e o Sudeste. As mesorregiões que mais se destacam são Salvador (BA), no padrão "Alto-Baixo", e São Paulo (SP), Campinas (SP), Piracicaba (SP), Curitiba (PR) e Florianópolis (SC), no padrão "Alto-Alto" (Figura 1c).

Alguns subdomínios tecnológicos componentes desse cluster têm nos residentes a maior participação, como o consumo das famílias $(74,2 \%)$, aparelhos agrícolas e alimentares $(68,28 \%)$, construção civil $(63,22 \%)$, procedimentos térmicos $(57,13 \%)$ e manutenção e gráfica (52,59\%) - Lemos et al. (2009).

$\mathrm{O}$ quarto cluster inclui as classes relacionadas às tecnologias elétricas e eletrônicas, possuindo setores de componentes elétricos, audiovisual, telecomunicações, informática, semicondutores, ótica e de análise, mensuração e controle. Nota-se que a autocorrelação espacial configura-se novamente como positiva, destacando-se as mesorregiões do Sul e Sudeste. Destacam-se no padrão "Alto-Baixo" as mesorregiões de Fortaleza (CE) e Manaus (AM) e no padrão "Alto-Alto" as mesorregiões de São Paulo (SP), Campinas (SP), Piracicaba (SP) e Curitiba (PR) - Figura 1d.

Lemos et al. (2009) esclarecem que alguns dos subdomínios tecnológicos componentes desse cluster (telecomunicações, semicondutores e informática) possuem mais de $80 \%$ de seus registros realizados por não-residentes. Dessa forma, há presença marcante de empresas, subsidiárias de multinacionais, líderes no mercado mundial, em áreas de livre tributação, como na Zona Franca de Manaus. 
Manaus destaca-se na produção eletrônica de consumo, ancorada em incentivos fiscais. Possui a presença de várias grandes empresas multinacionais que, em sua maioria, restringem o processo de $\mathrm{P} \& \mathrm{D}$ à sua sede e apenas registram sua patente no Brasil para resguardar direitos autorais. Dessa forma, a região não se constitui como um cluster geográfico com potencial para geração própria de tecnologia.

Em resumo, um padrão de localização concentrado em torno de poucas mesorregiões caracteriza a distribuição da atividade tecnológica brasileira nos quatro agrupamentos setoriais analisados. Em todos, emergem de forma recorrente as mesorregiões de São Paulo (SP), Campinas (SP), Piracicaba (SP), Curitiba (PR). Apenas nos casos de tecnologias eletroeletrônicas e desenvolvimento de novos materiais é que se destacam também as mesorregiões de Manaus (AM) e Florianópolis (SC), respectivamente, além das outras já citadas. Mesorregiões do Nordeste são consideradas como padrões "AltoBaixo" apenas nos casos de Fortaleza (bio-farmacêutico e eletroeletrônico) e Salvador (bens mecânicos e de consumo). As outras mesorregiões do País, particularmente do Nordeste e do Norte, caracterizam-se pelo padrão "Baixo-Baixo", enquanto o padrão "Baixo-Alto" localiza-se no entorno das principais mesorregiões (padrão "Alto-Alto") mencionadas anteriormente, em geral no Sudeste e Sul.

Os resultados corroboram aqueles encontrados por Diniz e Gonçalves (2001) que estabelecem três grandes regiões no que tange à inovação tecnológica. A primeira, denominada "Região Dinâmica" possui uma rede de cidades urbanizadas e integradas com boas condições de expansão e modernização econômica. A "Região Vazia”, definida por Centro-Oeste e Norte, constitui-se como grande produtora de commodities agropecuária e mineral. A "Região Atrasada” é composta pelo Nordeste e, apesar de contar com "ilhas" de produção tecnológica, mantém-se com menor potencial de desenvolvimento tecnológico.

\subsection{RESULTADOS ECONOMÉTRICOS}

A Tabela 4 apresenta os resultados das regressões dos determinantes das patentes per capita brasileiras pela estimação através do método dos Mínimos Quadrados Ordinários.

Todas as variáveis são significativas ao nível de $5 \%$, com exceção da variável referente ao $\mathrm{P} \& \mathrm{D}$ empresarial (PD), que se apresenta significativa a $10 \%$.

Os sinais das variáveis são positivos, conforme esperado. A densidade de emprego (DENSPO) apresenta-se como fator que influencia positivamente a atividade inovadora, da mesma forma que a capacidade de realização de $\mathrm{P} \& \mathrm{D}$ universitário (PHDPOP) e a capacidade de P\&D empresarial. Evidencia-se que a variável binária (NORSUL) é significativa e positiva, corroborando evidências anteriores que mostram diferenças marcantes nos sistemas regionais de inovação entre Sudeste e Sul, de um lado, e Norte, Centro-Oeste e Nordeste, de outro lado. Estas apresentariam relativa homogeneidade em termos de baixa atividade tecnológica, medida por patentes. Em que pesem as diferenças metodológicas relativas à forma funcional e ao nível de agregação regional utilizado, percebe-se semelhanças quanto aos resultados gerais das estimações, encontrados por Gonçalves e Almeida (2009). 
TABELA 4 - Determinantes da atividade tecnológica nas mesorregiões brasileiras: estimação por Mínimos Quadrados Ordinários

\begin{tabular}{|c|c|c|c|}
\hline \multicolumn{2}{|l|}{ Variáveis } & Coeficiente & Probabilidade \\
\hline \multicolumn{2}{|l|}{ Constante } & $-0,15$ & 0,37 \\
\hline \multicolumn{2}{|l|}{ DENSPOP } & 0,01 & 0,00 \\
\hline \multicolumn{2}{|l|}{ PHDPOP } & 0,12 & 0,02 \\
\hline \multicolumn{2}{|l|}{$\mathrm{PD}$} & 5,60 & 0,08 \\
\hline \multicolumn{2}{|l|}{ NORSUL } & 0,64 & 0,00 \\
\hline \multicolumn{2}{|l|}{$\mathrm{R}^{2}$ (ajustado) } & 0,39 & - \\
\hline \multicolumn{2}{|c|}{ Condição de multicolinearidade } & 7,06 & - \\
\hline \multicolumn{2}{|c|}{ AIC } & 227,79 & - \\
\hline \multicolumn{2}{|l|}{ Estatística de Jarque-Bera } & $1.328,87$ & 0,00 \\
\hline \multicolumn{2}{|l|}{ Teste de Koenker-Basset } & 6,62 & 0,16 \\
\hline \multicolumn{2}{|l|}{ Teste de White } & 8,96 & 0,78 \\
\hline Matrizes de pesos especiais & Testes & Coeficiente & Probabilidade \\
\hline W_QUEEN & $\begin{array}{l}\text { LM-ERR } \\
\text { LM-ERR (robusto) } \\
\text { LM-LAG } \\
\text { LM-LAG (robusto) } \\
\text { LM-SARMA }\end{array}$ & \begin{tabular}{|l|}
3,06 \\
0,38 \\
4,63 \\
1,95 \\
5,01 \\
\end{tabular} & \begin{tabular}{|l|}
0,08 \\
0,54 \\
0,03 \\
0,16 \\
0,08 \\
\end{tabular} \\
\hline W_INVDIST2 & $\begin{array}{l}\text { LM-ERR } \\
\text { LM-ERR (robusto) } \\
\text { LM-LAG } \\
\text { LM-LAG (robusto) } \\
\text { LM-SARMA }\end{array}$ & \begin{tabular}{l|l|}
8,89 \\
0,59 \\
11,96 \\
3,65 \\
12,54 \\
\end{tabular} & $\begin{array}{l}0,00 \\
0,44 \\
0,00 \\
0,06 \\
0,00 \\
\end{array}$ \\
\hline W_TECH & $\begin{array}{l}\text { LM-ERR } \\
\text { LM-ERR (robusto) } \\
\text { LM-LAG } \\
\text { LM-LAG (robusto) } \\
\text { LM-SARMA }\end{array}$ & \begin{tabular}{|l|}
6,03 \\
0,38 \\
26,43 \\
20,78 \\
26,81 \\
\end{tabular} & $\begin{array}{l}0,01 \\
0,54 \\
0,00 \\
0,00 \\
0,00 \\
\end{array}$ \\
\hline W_PQUEEN & $\begin{array}{l}\text { LM-ERR } \\
\text { LM-ERR (robusto) } \\
\text { LM-LAG } \\
\text { LM-LAG (robusto) } \\
\text { LM-SARMA } \\
\end{array}$ & \begin{tabular}{|l|}
0,00 \\
2,52 \\
18,36 \\
20,88 \\
20,88 \\
\end{tabular} & $\begin{array}{l}0,98 \\
0,11 \\
0,00 \\
0,00 \\
0,00 \\
\end{array}$ \\
\hline W_PQUEEN2 & $\begin{array}{l}\text { LM-ERR } \\
\text { LM-ERR (robusto) } \\
\text { LM-LAG } \\
\text { LM-LAG (robusto) } \\
\text { LM-SARMA } \\
\end{array}$ & \begin{tabular}{|l|}
0,89 \\
0,65 \\
21,24 \\
21,00 \\
21,90 \\
\end{tabular} & $\begin{array}{l}0,33 \\
0,42 \\
0,00 \\
0,00 \\
0,00 \\
\end{array}$ \\
\hline W_PQUEEN3 & $\begin{array}{l}\text { LM-ERR } \\
\text { LM-ERR (robusto) } \\
\text { LM-LAG } \\
\text { LM-LAG (robusto) } \\
\text { LM-SARMA } \\
\end{array}$ & \begin{tabular}{|l|}
1,26 \\
1,26 \\
20,31 \\
20,18 \\
21,57 \\
\end{tabular} & $\begin{array}{l}0,26 \\
0,26 \\
0,00 \\
0,00 \\
0,00 \\
\end{array}$ \\
\hline$\overline{\text { W_PINVDIST }}$ & $\begin{array}{l}\text { LM-ERR } \\
\text { LM-ERR (robusto) } \\
\text { LM-LAG } \\
\text { LM-LAG (robusto) } \\
\text { LM-SARMA }\end{array}$ & \begin{tabular}{|l|}
0,71 \\
0,54 \\
21,52 \\
21,35 \\
22,06 \\
\end{tabular} & $\begin{array}{l}0,40 \\
0,46 \\
0,00 \\
0,00 \\
0,00\end{array}$ \\
\hline
\end{tabular}

Fonte: Elaboração própria com base no programa SpaceStat 1.91 . 
O modelo apresenta $\mathrm{R}^{2}$ de 0,39 e inexistência de multicolinearidade. Através das estatísticas de teste de Konker-Basset e White, nota-se que os resíduos são homocedásticos. Porém, a estatística do teste Jarque-Bera acusa não-normalidade dos resíduos. Nesse caso, a estimação fornece estimativas $\beta$ inconsistentes e tendenciosas. Os coeficientes devem ser novamente estimados através de um método capaz de corrigir estes problemas. Os testes de diagnóstico espacial em geral rejeitam a hipótese de ausência de autocorrelação espacial, indicando má especificação do modelo e algum tipo de externalidade através das mesorregiões.

Para indicar a forma de dependência espacial (defasagem espacial no erro ou na variável dependente), utiliza-se o procedimento desenvolvido por Florax et al. (2003). Nos casos em que o teste LM-ERR não é significativo a 5\%, a melhor alternativa para lidar com a dependência espacial é através da inclusão da variável dependente defasada espacialmente. Nos casos em que o teste LM-ERR e o teste LM-LAG são significativos ao nível de $5 \%$, verificam-se as versões robustas destes testes para decidir qual o mais significativo. Nesse critério, em todos os casos (W_INVDIST2 e W_TECH), o maior valor estatístico ou menor valor de probabilidade sempre é favorável ao teste LM-LAG (rob). Dessa forma, a melhor opção para modelar a autocorrelação espacial é a inclusão da variável dependente defasada espacialmente.

Há indícios de que o processo de dependência espacial em relação à proximidade geográfica é menos forte que aquele referente à proximidade tecnológica, se considerados os valores estatísticos do teste LM-LAG da matriz tecnológica pura (W_TECH), que é igual a 26,43, e o do teste LM-LAG das matrizes espaciais puras (W_QUEEN ou W_INVDIST2), que são, respectivamente, 4,63 e 11,96. Por outro lado, quando ambas as matrizes de pesos, espacial e tecnológica, são usadas simultaneamente também é observada uma autocorrelação significativa, mas apresentam estatísticas do teste LM-LAG menores que o da matriz tecnológica pura. Em outras palavras, vizinhança tecnológica pura e vizinhança geográfica ponderada pela tecnológica aparentam ser mais importantes que vizinhança geográfica pura para mesorregiões brasileiras.

Nesse aspecto particular, esse resultado difere daquele encontrado por Moreno et al. (2005b) para regiões européias, em que os fatores geográficos pareciam dominar os fatores puramente tecnológicos. No caso brasileiro, externalidades geográficas de conhecimento tecnológico parecem ser mais efetivas quando há similaridade em determinados campos tecnológicos, uma vez que as trocas de cooperação e informação podem ser mais intensas. No caso de mesorregiões muito diferentes em termos tecnológicos, o conhecimento proveniente da vizinhança geográfica pode não ser diretamente aplicável e/ou requerer adaptações.

A Tabela 5 apresenta o modelo de Mínimos Quadrados em 2 Estágios (MQ2E), que é a melhor alternativa para lidar simultaneamente com a dependência espacial na forma de variável dependente defasada espacialmente e com o problema de nãonormalidade dos resíduos. 


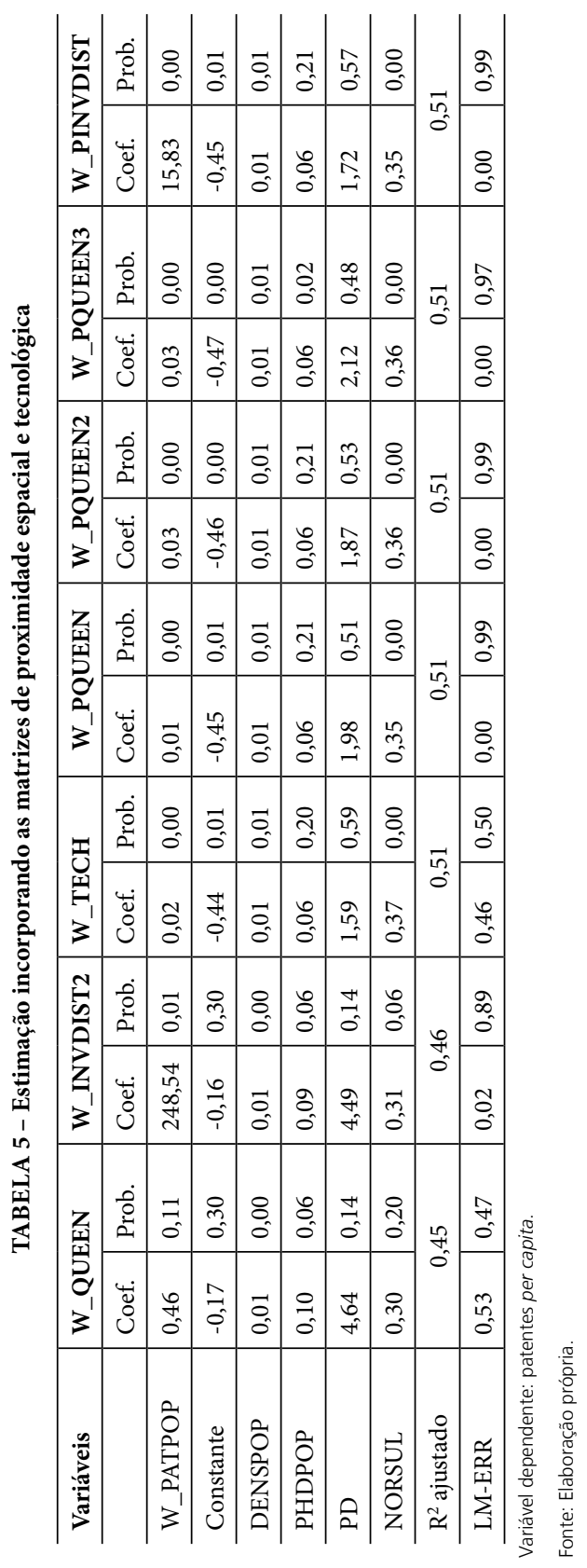


Nota-se que o grau de ajuste do modelo melhora substancialmente em relação ao da Tabela 4, por MQO. Outro aspecto que cabe destacar refere-se aos valores das estatísticas de significância apresentadas nos testes de LM-ERR, que não são significativos estatisticamente. Isso significa que os modelos não possuem autocorrelação espacial remanescente.

A Tabela 5 mostra que os sinais dos coeficientes apresentam-se conforme esperado, de acordo com a literatura internacional e nacional. A variável referente à densidade de emprego (DENSPO) apresenta-se estatisticamente significativa ao nível de 5\% em todas as estimações, corroborando a importância já destacada das aglomerações urbanas na atividade tecnológica brasileira, como nos resultados por microrregiões geográficas de Gonçalves e Almeida (2009). O resultado também é coerente com o papel desempenhado pelas economias de aglomeração na explicação das desigualdades salariais urbano-industriais no Brasil (GALINARI et al., 2007). Para os autores, as externalidades do tipo Jacobs, ou seja, a diversidade de atividades desenvolvidas nas cidades, são os principais fatores propulsores da produtividade do trabalho, dos salários e da sustentabilidade do crescimento de longo prazo das cidades.

Outro resultado obtido, embora contrário ao esperado, é a não-significância da capacidade de realizar P\&D empresarial (PD). A razão para isso pode estar relacionada à qualidade da proxy usada, que não se refere efetivamente a gastos em $\mathrm{P} \& \mathrm{D}$ como insumo da atividade inovadora.

O comportamento observado da variável que mede a capacidade universitária de P\&D (PHDPOP) revela significância estatística em alguns modelos, particularmente naqueles que consideram somente a proximidade geográfica, como nos casos das matrizes W_QUEEN e W_INVDIST2. Tal resultado é semelhante ao obtido por Gonçalves e Almeida (2009). Por outro lado, é possível notar que, das cinco especificações que utilizam o conceito de proximidade tecnológica, apenas uma (W_PQUEEN3) reconhece a importância da variável PHDPOP para a atividade inovadora. Isso mostra que os resultados que consideram apenas conceitos de vizinhança geográfica podem, de fato, superestimar a contribuição média da capacidade universitária de realizar $\mathrm{P} \& \mathrm{D}$ para a atividade inovadora regional. Entretanto, esses resultados gerais não podem desqualificar a importância das universidades para a inovação regional. Esse tema requer esforços adicionais de pesquisa que relacione o tipo de inovação gerada e a área de conhecimento principal das instituições de ensino e pesquisa da região.

A variável dummy vinculada ao regime de polarização Norte-Sul apresenta-se significativa em todas as estimações apresentadas, exceto nas matrizes que abordam somente a dependência espacial W_QUEEN e W_INVDIST2. Quando se considera somente a matriz de proximidade tecnológica ou ambas as matrizes (espacial e tecnológica) nas análises, a variável torna-se significativa em todos os modelos. 
No que se refere aos resultados que estão relacionados à variável dependente defasada espacialmente (W_PATPOP), nota-se que no modelo com matriz de pesos espaciais pura (coluna W_QUEEN) não haveria transbordamentos de conhecimento entre mesorregiões, quando se considera o critério de vizinhança Queen (regiões que fazem fronteira comum). Entretanto, outra matriz de pesos espaciais pura (coluna W_INVDIST2) mostra que, quando todas as mesorregiões são consideradas e cada uma exerce influência na razão inversa do quadrado da distância entre elas, a hipótese de transbordamentos de conhecimento se mantém. Esse resultado, comparado ao de Gonçalves e Almeida (2009), mostra que a hipótese de transbordamentos é válida tanto para microrregiões quanto para mesorregiões geográficas.

Quando a variável dependente defasada espacialmente (W_PATPOP) é a soma ponderada das patentes das mesorregiões vizinhas, sendo os pesos proporcionais à proximidade das firmas no "espaço tecnológico" (coluna W_TECH), verifica-se sua significância estatística a $1 \%$. Além disso, com base no grau de ajuste dos modelos $\left(\mathrm{R}^{2}\right)$ que aumenta de $46 \%$ para $51 \%$, nota-se que a proximidade tecnológica contribui para explicar a variabilidade das patentes per capita.

Em resumo, as evidências da Tabela 5 mostram, principalmente, que a proximidade tecnológica e a geográfica, ponderada pela tecnológica, são importantes como determinantes da atividade tecnológica regional. Isso quer dizer que os transbordamentos são mediados não só geograficamente, mas principalmente tecnologicamente. Em que pesem algumas diferenças metodológicas ${ }^{5}$, os resultados para o Brasil corroboram outros encontrados para estados norte-americanos (ORLANDO, 2000), regiões de países europeus (GREUNZ, 2003; MORENO et al., 2005b) e para divisões administrativas francesas (AUTANT-BERNARD, 2001).

\section{CONSIDERAÇÕES FINAIS}

Esse artigo investigou se a vizinhança geográfica e a tecnológica importam para a ocorrência de transbordamentos de conhecimento tecnológico no Brasil. Foi usada uma amostra de depósito de patentes que cobriu o período 1999-2001 para 121 mesorregiões geográficas brasileiras, a qual foi submetida à AEDE e à análise econométrica-espacial. Os dados de patentes foram organizados e agrupados segundo critério de proximidade cognitiva, dando origem a quatro clusters tecnológicos: biofarmacêutico, desenvolvimento de novos materiais, bens mecânicos e de consumo e tecnologias eletroeletrônicas. Além disso, foi calculada uma medida de proximidade tecnológica, que pudesse ponderar a vizinhança geográfica pelo grau de similaridade tecnológica das mesorregiões.

\footnotetext{
${ }^{5}$ Referentes às proxies usadas e aos métodos econométricos utilizados.
} 
Os resultados da AEDE confirmam a existência de um regime de polarização da atividade tecnológica brasileira. As macrorregiões Norte, Nordeste e Centro-Oeste são caracterizadas por regimes tecnológicos do tipo "Baixo-Baixo" na maior parte de suas mesorregiões geográficas, enquanto os regimes "Alto-Baixo" despontam em algumas poucas mesorregiões, como Manaus (tecnologia eletroeletrônicas), Fortaleza (biofarmacêutico e tecnologias eletroeletrônicas) e Salvador (bens mecânicos e de consumo). Sudeste e Sul possuem mesorregiões pertencentes ao regime "Alto-Alto" e "Baixo-Alto". No caso do regime "Alto-Alto", as mesorregiões de São Paulo (SP), Campinas (SP), Piracicaba (SP) e Curitiba (PR) destacam-se em todos os tipos de clusters. Isso revela que a atividade tecnológica brasileira segue padrão concentrado, independentemente do tipo de tecnologia, quando a análise é realizada por mesorregiões geográficas.

Em termos de resultados econométricos, observou-se que a densidade de emprego, que representa economias de aglomeração, é importante na determinação da atividade tecnológica brasileira. Em relação à capacidade de pesquisa universitária, nota-se sua significância em três das seis especificações usadas, validando empiricamente, ao menos parcialmente, a relação entre capacidade de realizar $\mathrm{P} \& \mathrm{D}$ universitário e atividade tecnológica. No caso da capacidade de $\mathrm{P} \& \mathrm{D}$ empresarial, os resultados não confirmam, com a proxy usada nesse artigo, a expectativa teórica.

O principal resultado, porém, é a confirmação de que não só a influência exercida pela proximidade geográfica como também a similaridade tecnológica das regiões exerce efeito determinante sobre a geração de inovações. Esse resultado revela que a inovação de determinada mesorregião é positivamente influenciada pela atividade tecnológica das mesorregiões vizinhas, com especial ênfase quando o conceito de vizinhança usado é o tecnológico e o geográfico ponderado pelo grau de similaridade tecnológica dos vizinhos.

Os resultados podem ser úteis para a elaboração de políticas públicas que visem contribuir para a construção e fortalecimento de sistemas regionais de inovação. Para tanto, é importante conduzir uma maior integração entre políticas industriais e tecnológicas, pois os resultados mostram que o grau de similaridade tecnológica das regiões importa para ocorrência de transbordamentos, sendo estes um pré-requisito para acesso a externalidades positivas que fomentam o processo de crescimento econômico, principalmente no caso de regiões que possuem condições de absorção dos transbordamentos.

Como direções futuras de pesquisa, o artigo aponta para a necessidade de investigar a ocorrência de transbordamentos de conhecimento tecnológico em função do grau de especialização tecnológica das regiões, especialmente dos clusters tecnológicos definidos em função da proximidade cognitiva. O papel de agentes constituintes dos sistemas regionais de inovação prevalecentes no Brasil pode ser destacado, principalmente a influência de instituições de ensino e pesquisa sobre o desempenho tecnológico regional. 


\section{REFERÊNCIAS}

ALBUQUERQUE, E. M.; SIMÕES, R.; BAESSA, A.; CAMPOLINA, B.; SILVA, L. “A distribuição espacial da produção científica e tecnológica brasileira: uma descrição de estatísticas de produção local de patentes e artigos científicos. Revista Brasileira de Inovação, Rio de Janeiro, v. 1, n. 2, p. 225-251, 2002.

ALMEIDA, P.; KOGUT, B. "Localization of knowledge and the mobility of engineers in regional networks. Management Science, v. 45, n. 7, jul., 1999.

AMIN, A.; THRIFT, N. Living in the global. In: AMIN, A.; THRIFT, N. (Ed.). Globalization, institutions, and regional development in Europe. Oxford: Oxford University, 1994. p. 1-22.

ANSELIN, L. Spatial econometrics. Dallas: University of Texas Press, 1999.

ANSELIN, L. Spatial econometrics: methods and models. Boston: Kluwer Academic, 1988. p. 284.

ARROW, K. J. “The economic implications of learning by doing. Review of Economic Studies, v. 29, p. 155-172, 1962.

AUDRETSCH, D. B.; FELDMAN, M. P. “R\&D spillovers and the geography of innovation and production. American Economic Review, v. 86, n. 3, p. 630-640, 1996.

AUTANT-BERNARD, C. “The geography of knowledge spillovers and technological proximity. Economics of Innovation and New Technology, v. 10, p. 237-254, 2001.

BLACK, D.; HENDERSON, V. “A theory of urban growth. Journal of Political Economy. v. 107, n. 2, 1999.

BRESCHI, S.; LISSONI, F.; MALERBA, F. Knowledge Proximity and Firms' Technological Diversification. mimeo, CESPRI, Università L. Bocconi, 1998.

BRESCHI, S.; LISSONI, F.; MALERBA, F. Knowledge Relatedness in Firm Technological Diversification. Research Policy. v. 32, n. 1, p. 69-87, 2003.

DE NEGRI, J. A.; SALERNO, M. S.; CASTRO, A. B. Estratégias competitivas e padrões tecnológicos das firmas na indústria brasileira. Brasília: IPEA, 2004. (mimeo).

DINIZ C. C.; GONÇALVES, E. “Knowledge economy and regional development in Brazil. In: The third Congress on proximity. Paris. Les troisièmes journées de la proximité, 2001.

DOMAR, E. “Capital Expansion, Rate of Growth and Employment. Econometrica, v. 14, p. 137-147, 1946.

FAGGIAN, A.; McCAN, P. Human Capital Flows and Regional Knowledge Assets: A Simultaneous Equation Model. ERSA Congress Papers, 2004.

FELDMAN, M. P. “The new economics of innovation, spillovers and agglomeration: a review of empirical studies. Economics of Innovation and New Technology, v. 8, p. 05-25, 1999.

FELDMAN, M. P.; AUDRETSCH, D. B. "Innovation in cities: science-based diversity, specialization and localized competition. European Economic Review, v. 43, p. 409-429, 1999. 
FELDMAN, M. P.; FLORIDA, R. “The geographic sources of innovation: technological infrastructure and product innovation in the United States". Annals of the Association of American Geographers. v. 84, n. 2, p. 210-229, 1994.

FISCHER, M. M.; VARGA, A. “Spatial knowledge spillovers and university research: evidence from Austria”. Annals of Regional Science, v. 37, p. 303-322, 2003.

FLORAX, R. J. G. M.; FOLMER, H.; REY, S. J. "Specification searches in spatial econometrics: the relevance of Hendry's methodology". Regional Science and Urban Economics, v. 33, p. 557-579, 2003.

GALLIÉ, E. "Is geographical proximity necessary for knowledge spillovers within a cooperative technological network? The case of the French biotechnology sector". Regional Studies, v. 43, n. 1, p. 33-42, 2009.

GALINARI, R.; CROCCO, M.; LEMOS, M.; BASQUES, M. “O efeito de aglomeração sobre os salários industriais: uma aplicação ao caso brasileiro". Revista de Economia Contemporânea, v. 11, n. 3, p. 391-420, 2007.

GLAESER, E. L.; KALLAL, H. D.; SCHEINKMAN, J. A.; SHLEIFER, A. “Growth in cities”. Journal of Political Economy, v. 100, n. 6, 1992.

GERTLER, M. S. “Tacit knowledge and the economic geography of context, or The undefinable tacitness of being (there)". Journal of Economic Geography, v. 3, p. 75-99,2003.

GONÇALVES, E. “A distribuição espacial da atividade inovadora brasileira: uma análise exploratória”. Estudos Econômicos, São Paulo, v. 37, n. 2, p. 405-433, 2007.

GONÇALVES, E.; ALMEIDA, E. S. “Innovation and Spatial Knowledge Spillovers: Evidence from Brazilian Patent Data”. Regional Studies, v. 43, p. 513-528, mai. 2009.

GREUNZ, L. "Geographically and technologically mediated knowledge spillovers between European regions". Annals of Regional Science. v. 37, p. 657-680, 2003.

GRILICHES, Z. "Patent statistics as economic indicators: a survey". Journal of Economic Literature. v. 28, p. 1.661-1.707, 1979.

HENDERSON, J. V. Understanding knowledge spillovers. Regional Science and Urban Economics, v. 37, p. 497-508, 2007.

JAFFE, A. B. “Technological opportunity and spillovers of R\&D: evidence from firms' patents, profits, and market value”. American Economic Review, v. 76, n. 5, p. 984-1.001, 1986.

JAFFE, A. B. "Real effects of academic research". American Economic Review, v. 79, n. 5, p. 957-970, 1989.

JAFFE A. B.; TRAJTENBERG, M.; HENDERSON. R. “Geographic localization of knowledge spillovers as evidenced by patent citations”. Quarterly Journal of Economics. v. 108, n. 3, p. 577-598, 1993. 
KOO, J. "Determinants of localized technology spillovers: role of regional and industrial attributes”. Regional Studies, v. 41, p. 995-1.011, 2007.

LEMOS, M. B. S.; MORO, E. P.; DOMINGUES e RUIZ, R. M. A Organização Territorial da Indústria no Brasil. In: NEGRI, J. A. e SALERMO, M. (Ed.). Inovação, Padrões Tecnológicos e Desempenho das Firmas Industriais Brasileiras. Brasília: IPEA, 2005.

LEMOS, M. B.; DOMINGUES, E. P.; AMARAL, P. V.; RUIZ, R. M.; ARAÚJO, R.; CALIARI, T. Complexo da Saúde. In: Estudo sobre como as empresas brasileiras nos diferentes setores industriais acumulam conhecimento para realizar inovação tecnológica. Brasília: ABDI, 2009.

LUCAS, R. E. “On the mechanisms of economic development”. Journal of Monetary economics. v. 22, p. 3-42, 1988.

MALECKI, E. J. Technology and economic development: the dynamics of local, regional, and national change. New York: Longman, 1997.

MORAN, P. A. P. The interpretation of statistical maps. Journal of the Royal Statistical Society. v. 10, p. 243-251, 1948.

MORENO, R.; PACI, R.; USAI, S. "Geographical and sectoral clusters of innovation in Europe". Annals of Regional Science, v. 39, p. 715-739, 2005a.

MORENO, R.; PACI, R.; USAI, S. "Spatial spillovers and innovation activity in European regions”. Environment and Planning A, v. 37, p.1.793-1.812, $2005 \mathrm{~b}$.

NELSON, R.; WINTER, S. G. An evolutionary theory of economic change. Cambridge: Harvard University, p. 437, 1982.

ORLANDO, M. J. Measuring R \& D spillovers: on the importance of geographic and technological proximity. Federal Reserve Bank of Kansas City, jul. de 2000. (Research Working Paper, n. 2).

OBSERVATOIRE DES SCIENCES ET DES TECHNIQUES - OST. Science \& Technologie: indicateurs 2000. Paris: Economica, 2000.

PACI, R.; USAI, S. Knowledge flows across european regions. CRENOS Working Papers, n. 4, 2007.

PATEL, P.; PAVITT, K. Patterns of technological activity: their measurement and interpretation. In: STONEMAN, P. (Org.) Handbook of the Economics of Innovation and Technological Change. Oxford: Blackwell, 1995.

POLANYI, M. The Tacit Dimension. In: PRUSAK, L. Knowledge in Organizations. Nova Iorque: Harper \& Row, 1987.

PRICE, D. J. S. Networks of Scientific Papers. Science. v. 149, n. 3.683, p. 510-515, 1965.

RALLET, A.; TORRE, A. "Is geographical proximity necessary in the innovation networks in the era of global economy”. GeoJournal, v. 49, p. 373-380, 1999.

ROMER, P. “Endogenous technological change”. Journal of Political Economy. v. 98, p. 71-102, 1990. 
SCHERER, F. M. "Using Linked Patent and R\&D Data to Measure Interindustry Technology Flows”. Review of Economics and Statistics. v. 64, p. 627-634, 1982.

SIMMIE, J. Innovation and agglomeration theory. In: SIMMIE, J. (Ed.), Innovative cities. New York: Spon Press, p. 11-52, 2001.

SOLOW, R. M. "A contribution to the theory of economic growth". Quarterly Journal of Economics, v. 70, p. 65-94, 1956.

TORRE, A. "On the role played by temporary geographical proximity in knowledge transmission”. Regional Studies, v. 42, n. 6, p. 869-889, 2008.

VARGA, A. University Research and Regional Innovation:a spatial econometric analysis of academic technology transfers. Boston/Dordrecht/Londres: Kluwer Academic Publishers, 1998.

VERSPAGEN, B. "Measuring inter-sectoral technology spillovers: Estimates from the European and US patent office databases”. Economic Systems Research. v. 9, n. 1, p. 49-67, 1997. 